\title{
Arsenic Distribution in a Tilapia (Oreochromis mossambicus) Water-Sediment Aquacultural Ecosystem in Blackfoot Disease Hyperendemic Areas
}

\author{
S. -W. Wang · K. -H. Lin · Y. -M. Hsueh · \\ C. -W. Liu
}

Published online: 6 April 2007

(C) Springer Science+Business Media, LLC 2007

Arsenic (As) contamination of groundwater is a major environmental concern (Smedley and Kinniburgh, 2002). In Taiwan, high arsenic concentrations in deep well water have been verified to be associated with blackfoot disease (BFD), which was once common on the southwestern coastal area (Tseng, 1997). From 1999 to 2004, the Taiwan Sugar Company undertook a groundwater quality survey at monitoring wells in this area (Taiwan Sugar Company, 2004). The As concentration in groundwater was $0.30 \pm$ $0.35 \mathrm{mg} / \mathrm{L}$. At around $95 \%$ of monitoring in wells, the As concentrations exceeded the World Health Organization (WHO) guideline of $0.01 \mathrm{mg} / \mathrm{L}$. Nowadays, even though this well water is not directly ingested by most inhabitants in this hazardous region, it is still extensively provided to meet domestic, irrigation, aquacultural and industrial needs. In the aquacultural sector, in particular, high As concentrations are bioaccumulated in tilapia (Han et al., 1998). The inorganic As concentrations of the farmed fish have increased with the As concentration of pond water in this area (Huang et al., 2003), causing a potential cancer risk (Liu et al., 2005). The decreased survival and reduced

\section{S. -W. Wang · C. -W. Liu ( $\square)$}

Department of Bioenvironmental Systems Engineering,

National Taiwan University, Taipei, Taiwan 106,

Republic of China

e-mail: lcw@gwater.agec.ntu.edu.tw

K. -H. Lin

Research Center for Environment and Resources Management, National Chen Kung University, Tainan, Taiwan 701,

Republic of China

Y. -M. Hsueh

Department of Public Health, School of Medicine,

Taipei Medical University, Taipei, Taiwan 110,

Republic of China reproductive ability of the fish were related to the accumulation of metals in aquatic organisms (Liao et al., 2003). The Taiwan Environmental Protection Administration (2001) investigated the As concentration in 160 wells in the BFD area. The As concentrations in 106 samples collected from these wells exceeded $0.05 \mathrm{mg} / \mathrm{L}$, and water from 44 out of the 106 wells was used for fish cultivation, especially for tilapia (Oreochromis mossambicus) farming. To understand the impact of As-containing groundwater on the accumulation and transformation of As in tilapia, researchers have evaluated the bioconcentration factor (BCF) using data collected from laboratory and field measurements (Suhendrayatna et al., 2002). The BCF, which relates the concentration of a metal in water to its concentration in an aquatic animal at equilibrium, is generally used to estimate the propensity to accumulate the metal in the organism. Chen and Liao (2004) measured the uptake and depuration rate constants of As by tilapia in the laboratory and found that the BCF was $3.2 \mathrm{ml} / \mathrm{g}$. Huang et al. (2003), however, estimated an average BCF of $41.8 \pm$ $31.4 \mathrm{ml} / \mathrm{g}$, based on As concentrations of pond water and tilapia collected from 21 ponds in the BFD areas.

The major difference between these two studies was the inclusion or exclusion of the sediment phase. To comprehend the influence of the sediment phase on the calculation of $\mathrm{BCF}$, the As concentrations of tilapia, pond water, and sediment in the aquacultural ecosystem was thus investigated in this study. As adsorption isotherm was determined by performing an adsorption experiment in a sediment-water system. Accordingly, a first-order two-compartment model was proposed to estimate the As concentration in tilapia, and the effect of the sediment phase on the distribution of As in the farmed tilapia ecosystem was quantified. The results are valuable to risk assessments of the ecological system and to human health in hyperendemic BFD areas. 


\section{Materials and Methods}

Tilapia, pond water, and sediment samples were taken from 8 fishponds at the same time in the BFD areas-Putai, Yichu, Peimen, and Hsuehchia, in Chiayi and Tainan counties, Taiwan. The water samples were collected in polyethylene containers, cleaned with $10 \%$ nitric acid and then rinsed with deionized water. Fish and sediment samples were placed in polyethylene bags. All samples were frozen for transport to the laboratory and stored at $-20^{\circ} \mathrm{C}$ until they were analyzed. The water samples were filtered through a $0.45 \mu \mathrm{m}$ filter before analyses. Specimens of the dorsal muscle of the fish were minced and blended to obtain homogeneous samples. A portion of homogeneous fish and sediment samples was freeze-dried for $36 \mathrm{~h}$. The $\mathrm{pH}$ and redox potential (Eh) of the pond water and sediment samples were measured in the field. The organic carbon content of sediment samples was determined by a modified Walkley-Black method (Donahue and Heckendorn, 1996).

To determine the total As concentration, homogenized freeze-dried fish and water samples were digested with $65 \%$ nitric acid until the solutions were clear, and overnight, respectively (Huang et al., 2003). For sediment samples, a $30 \% \mathrm{H}_{2} \mathrm{O}_{2}$ and $9.6 \mathrm{M} \mathrm{HCl}$ solution was added to remove organic matter. Afterward, all pretreated solutions were filtered, and the filtrates were collected and subjected to As analysis using an electrothermal atomic absorption spectrometer (AAS, Perkin-Elmer AA100) and a hydride generation (HG) system (Perkin-Elmer FIAS-400). With the addition of $0.5 \% \mathrm{NaBH}_{4}$ in $0.25 \% \mathrm{NaOH}$ and $1 \mathrm{~N} \mathrm{HCl}$, total As concentrations were determined.

To determine the concentrations of inorganic As species, water samples were filtered through $0.45 \mu \mathrm{m}$ filters before analyses. Homogenized freeze-dried fish samples and methanol/water solution were placed in a Soxhlet extraction apparatus and extracted for $16 \mathrm{~h}$. The methanol was removed by a methanol removal extraction tube after the extraction (Huang et al., 2003). The extract then was freeze-dried into powders and dissolved in $10 \mathrm{ml}$ of deionized water. The dissolved solution was purified by passing it through $\mathrm{C}_{18}$ cartridges. For sediment samples, $0.4 \mathrm{M} \mathrm{NH} \mathrm{N}_{2} \mathrm{OH} \cdot \mathrm{HCl}$ were added and heated at $95{ }^{\circ} \mathrm{C}$ for $8 \mathrm{~h}$. Then the suspensions were centrifuged at $10,000 \mathrm{rpm}$ for 10 min to obtain the supernatant. Finally, the separation of $\mathrm{As}^{3+}$ and $\mathrm{As}^{5+}$ in all treated samples was achieved by passing $200 \mu$ l of the samples through HPLC (Hitachi 7110, Naka, Japan) equipped with an anion column (MacheyNagel, Nucleosil, $10 \mu \mathrm{m}, 250 \times 4.6 \mathrm{~mm}$ ), which linked to $\mathrm{HG}$ and AAS.

The accuracy of the procedure was validated by the analysis of the standard reference material (SRM) BCR 627 tuna tissue. Total arsenic concentration of SRM was
$4.9 \pm 0.2 \mathrm{mg} / \mathrm{kg}$, consistent with the certified values of 4.8 $\pm 0.3 \mathrm{mg} / \mathrm{kg}$. The detection limits of total arsenic, $\mathrm{As}^{3+}$, and $\mathrm{As}^{5+}$ were $0.2,0.4$, and $0.2 \mu \mathrm{g} / 1$, respectively. Samples were spiked with arsenic species to calculate the recovery rate in every extraction step and laboratory procedure. The extraction recovery rates of $\mathrm{As}^{3+}$ and $\mathrm{As}^{5+}$ were $102.7 \pm$ $4.7 \%$ and $104.1 \pm 6.8 \%$, respectively. The laboratory procedure recovery rates of total $\mathrm{As}, \mathrm{As}^{3+}$, and $\mathrm{As}^{5+}$ were $103.2 \pm 7.1 \%, 100.7 \pm 3.8 \%$, and $97.2 \pm 4.0 \%$, respectively. The coefficient of variation was used to test the reliability and was less than 5\% for all experiments (Huang et al., 2003).

To estimate the rate constant for the uptake by tilapia from sediment, we first needed to determine the coefficients of the adsorption isotherm of $\mathrm{As}^{5+}$, the predominant inorganic As species of pond water and sediment (according to the results in this study). An adsorption experiment of $\mathrm{As}^{5+}$ was conducted using the sediment samples taken from fishponds \#1-\#4 in the BFD hyperendemic area. Next, $30 \mathrm{ml}$ of $0,0.5,1,5,10,20,30,40,50$, 75 , and $100 \mathrm{mg} / \mathrm{L}$ of $\mathrm{As}^{5+}$ solutions, which were prepared by $1,000 \mathrm{mg} / \mathrm{L} \mathrm{H}_{3} \mathrm{AsO}_{4}$ standard solution (preserved in 0.5 $\mathrm{ml} / \mathrm{L} \mathrm{HNO}_{3}$ ), were mixed individually with $3 \mathrm{~g}$ of four freeze-dried sediment samples in 50-ml centrifuge tubes. All of the batch experiments were conducted in triplicate. In all adsorption experiments, suspensions were shaken on a reciprocating shaker for $24 \mathrm{~h}$ at room temperature $\left(26^{\circ} \mathrm{C}\right)$, before being centrifuged at 10,000 rpm for $10 \mathrm{~min}$. The As concentrations of supernatants were analyzed by AAS and HG systems. Adsorption experiments were performed and fitted with the Langmuir equation, $\mathrm{C}_{\mathrm{s}}=\left(\mathrm{K}_{\mathrm{L}} \mathrm{C}_{\mathrm{w}} \mathrm{b}\right) /\left(1+\mathrm{K}_{\mathrm{L}} \mathrm{C}_{\mathrm{w}}\right)$. $\mathrm{C}_{\mathrm{w}}$ and $\mathrm{C}_{\mathrm{s}}$ denote the equilibrium concentrations of As in water and sediment, respectively. Mean values of coefficients of adsorption isotherms $\mathrm{K}_{\mathrm{L}}$ and $\mathrm{b}$ are used to estimate As concentration of tilapia by the first-order twocompartment model.

Since tilapia habitually disturbs the bottom sediment layer, it is postulated that As in both the sediment and water phases affects the As concentration accumulated in tilapia. In this study, we assume that the concentrations and speciation of As in the water and sediment phases remain constants - and thus time-independent—and are not affected by the tilapia uptake. Moreover, the uptake and depuration rate constants are the same for both $\mathrm{As}^{3+}$ and $\mathrm{As}^{5+}$, and the uptake rate of As from the sediment phase to tilapia is constant. A first-order two-compartment model was thus formulated to describe the uptake and transformation of total As by tilapia in the aquacultural ecosystem involving both water and sediment phases. The kinetic equation can be written as follows:

$\frac{d C_{f}(t)}{d t}=k_{1} C_{W}-k_{2} C_{f}(t)+K_{S} C_{S}$ 
After integrating Eq. (1) and applying the initial condition $\mathrm{C}_{f}(0)=0$ and $\mathrm{t}=\infty$, yields the steady-state solution of $\mathrm{C}_{f}$ as:

$C_{f}=\frac{k_{1} C_{W}+K_{S} C_{S}}{k_{2}}$

where $\mathrm{C}_{\mathrm{f}}(\mathrm{t})$ and $\mathrm{C}_{\mathrm{f}}$ are the transient and steady-state total As concentrations in tilapia $\left(\mathrm{mg} / \mathrm{kg}\right.$ ), respectively; $\mathrm{C}_{\mathrm{w}}$ is the equilibrium concentration of As species in pond water $(\mathrm{mg} / \mathrm{L}) ; \mathrm{C}_{\mathrm{s}}$ is the equilibrium concentration of As species in sediment $(\mathrm{mg} / \mathrm{kg}) ; \mathrm{k}_{1}$ is the uptake rate constant $(\mathrm{ml} / \mathrm{g} / \mathrm{d})$ and $\mathrm{k}_{2}$ is the depuration rate constant $(1 / \mathrm{d})$; and $\mathrm{K}_{\mathrm{s}}$ is the rate constant for the uptake by tilapia from sediment $(\mathrm{mg} /$ $\mathrm{mg} / \mathrm{d}$ ). Notably, the $\mathrm{K}_{\mathrm{s}}$ values of \#1-\#4 fishponds are calculated based on the experimental data. The determined $\mathrm{K}_{\mathrm{s}}$ are then used to estimate the As concentrations of tilapia in \#5-\#8 fishponds, and to validate the proposed first-order two-compartment model. The estimated As concentrations in tilapia considering the sediment phase are compared with those that do not consider the sediment phase.

\section{Results and Discussion}

Table 1 presents the analytical results of fishponds \#1-\#4 in the BFD hyperendemic. The $\mathrm{pH}$ values of the pond water (7.2-8.5) were mildly higher than those of the sediment phase (6.6-7.9). The Eh of the pond water was found to be oxidative (105-227 mV) while that of sediment was found to be reductive $(-190-137 \mathrm{mV})$. Redox condition and $\mathrm{pH}$ are the important factors that can control the formation of inorganic As species (Smedley and Kinniburgh, 2002). Generally, excrement of tilapia and surplus feed caused the amount of organic carbon to be enriched on the bottom surface sediment. The contents of organic carbon in this study are in the range of $2.4 \%-5.3 \%$, and may cause slightly acidic and reductive conditions in the saturated bottom sediment. The mobilization of As may be affected by organic carbon. Microbial degradation of organic carbon leads to reductive dissolution of As-coated $\mathrm{Fe}, \mathrm{Mn}$, and Al hydroxides. Organic carbon may compete with As for binding onto surfaces of solid phase. Moreover, complexation of As by organic carbon in the presence of metal cations indicates that organic carbon affects As mobility (Buschmann et al., 2006). After As-contained groundwater has been used in a fishpond, the As distribution of pond water may be dominated by organic carbon, which is adsorbed on the sediment surface.

The total As concentrations in pond water, sediment, and tilapia were $4.4-39.4 \mu \mathrm{g} / \mathrm{L}, 5.7-25.0 \mathrm{mg} / \mathrm{kg}$, and $357.3-1047.9 \mu \mathrm{g} / \mathrm{kg}$, respectively. The As concentrations of sediment are several orders higher than those of the tilapia (Table 1). The As concentration of tilapia is higher than that of marine fish, shellfish, and other freshwater fish (Donohue and Abernathy, 1999).

The other cultivated fish with high market value in the BFD area, mullet (Liza macrolepis) and milkfish (Chanos chanos), have also been exposed to the high-As pond
Table 1 Measured total As, $\mathrm{As}^{3+}$, and $\mathrm{As}^{5+}$ concentrations in pond water, sediment, and tilapia, and basic properties of sediment of fishponds \#1-\#4

\begin{tabular}{|c|c|c|c|c|c|}
\hline \multirow[t]{2}{*}{ Medium } & \multirow[t]{2}{*}{ Variables } & \multicolumn{4}{|c|}{ Fishpond \# } \\
\hline & & 1 & 2 & 3 & 4 \\
\hline \multirow[t]{6}{*}{ Pond water } & $\mathrm{pH}$ & 7.2 & 8.2 & 8.3 & 8.5 \\
\hline & $\mathrm{Eh}(\mathrm{mV})$ & 227 & 134 & 171 & 105 \\
\hline & $\mathrm{As}^{3+}(\mu \mathrm{g} / \mathrm{L})$ & 0.04 & $\mathrm{ND}^{\mathrm{a}}$ & 2.8 & 0.7 \\
\hline & $\mathrm{As}^{5+}(\mu \mathrm{g} / \mathrm{L})$ & 4.2 & 14.0 & 15.0 & 36.5 \\
\hline & Total As( $\mu \mathrm{g} / \mathrm{L})$ & 4.4 & 14.3 & 21.3 & 39.4 \\
\hline & $\%$ of inorganic As & 96.4 & 97.9 & 83.6 & 94.4 \\
\hline \multirow[t]{8}{*}{ Sediment } & $\mathrm{pH}$ & 6.6 & 7.9 & 7.6 & 7.8 \\
\hline & $\mathrm{Eh}(\mathrm{mV})$ & -137 & -190 & -180 & -180 \\
\hline & Specific gravity (kg/L) & 2.2 & 2.7 & 2.7 & 2.3 \\
\hline & Organic matter (\%) & 5.1 & 2.5 & 2.4 & 5.3 \\
\hline & $\mathrm{As}^{3+}(\mathrm{mg} / \mathrm{kg})$ & 0.3 & 0.8 & 0.4 & 1.4 \\
\hline & $\mathrm{As}^{5+}(\mathrm{mg} / \mathrm{kg})$ & 4.8 & 21.8 & 13.9 & 10.4 \\
\hline & Total As(mg/kg) & 5.7 & 25.0 & 15.1 & 13.0 \\
\hline & $\%$ of inorganic As & 89.5 & 90.4 & 94.7 & 90.8 \\
\hline \multirow[t]{4}{*}{ Tilapia } & $\mathrm{As}^{3+}(\mu \mathrm{g} / \mathrm{kg})$ & 9.5 & 25.3 & 19.7 & 3.8 \\
\hline & $\mathrm{As}^{5+}(\mu \mathrm{g} / \mathrm{kg})$ & 3.9 & 12.5 & 12.4 & 26.0 \\
\hline & Total As $(\mu \mathrm{g} / \mathrm{kg})$ & 441.9 & 1047.9 & 788.4 & 357.3 \\
\hline & $\%$ of inorganic As & 3.0 & 3.6 & 4.1 & 8.3 \\
\hline
\end{tabular}


Fig. 1 Arsenate adsorption isotherms for sediment samples taken from fishponds \#1-\#4
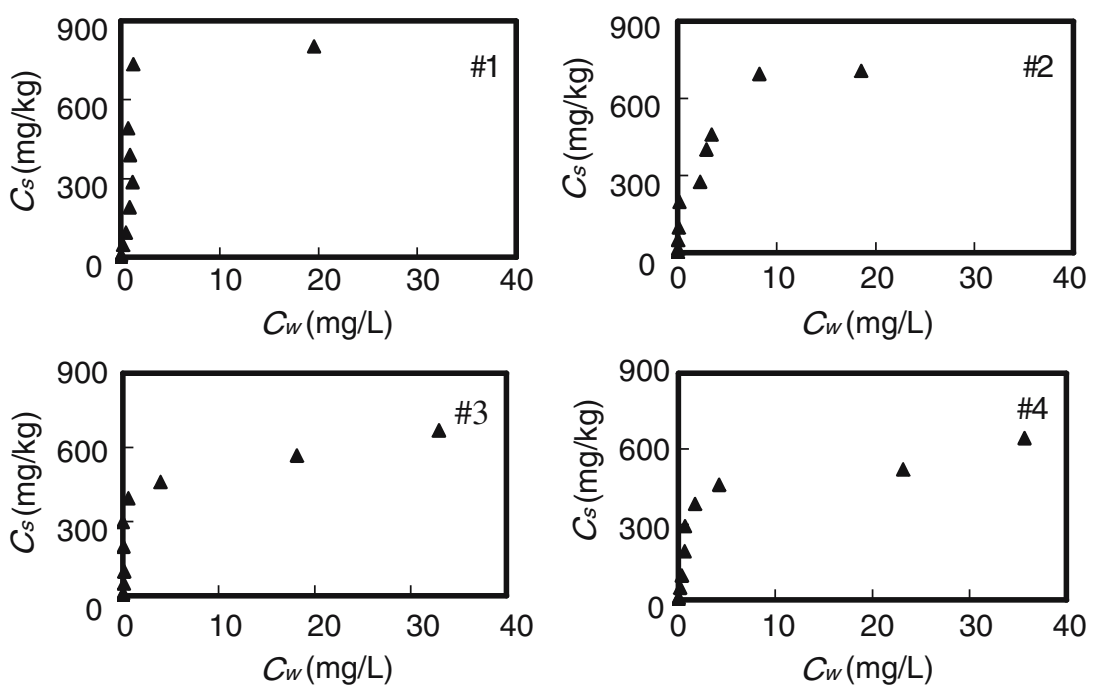

water, and posed a health risk to residents (Lin et al., 2005). These As distributions indicate that the sediment phase is likely a sink of As into the aquacultural ecosystem. Then, As-enriched sediment released As into the water under anaerobic conditions, and may have partially influenced the bioavailability of As to tilapia. In addition, the inorganic arsenic fractions in pond water (83.6$97.9 \%)$ and sediment phase (89.5-94.7\%) are higher than those in tilapia (3.0-8.3\%). The low inorganic As fraction in tilapia was attributable to the biotransformation of inorganic As to organic As by biomethylation (Suhendrayatna et al., 2002). The $\mathrm{As}^{5+}$ is the predominant form of the inorganic As in both the pond water and sediment phases. These field data yield an averaged $\mathrm{BCF}$ value, $55.0 \pm 40.1 \mathrm{ml} / \mathrm{g}$, which is higher than that obtained in the laboratory (Chen and Liao, 2004), and is close to that of other field investigations (Huang et al., 2003; Liao et al., 2003). The discrepancy of the two markedly different BCFs, calculated by two different methods using $\mathrm{k}_{1} / \mathrm{k}_{2}$ and $\mathrm{C}_{\mathrm{f}} / \mathrm{C}_{\mathrm{w}}$, may be elucidated by the inclusion of the sediment phase. Here we attribute the higher $\mathrm{BCF}$ observed in field measurements as a result of As uptake from the sediment phase, which is discussed in further detail later.
Figure 1 plots the $\mathrm{As}^{5+}$ adsorption isotherm results of the sediment samples collected from fishponds \#1-\#4. The $\mathrm{As}^{5+}$ adsorption isotherms show the adsorbed molecules were most likely adsorbed flat. The adsorbate is in an intermolecular relationship with the surface and competes with the water for the active adsorption centers of the surface. The averaged fitted parameters of \#1-\#4 sediments by the Langmuir adsorption isotherm, including $\mathrm{K}_{\mathrm{L}}$ and $\mathrm{b}$, are 438.3 and $2.5\left(R^{2}>0.95, p<0.05\right)$, respectively. The input parameters of the first-order two-compartment model were $\mathrm{C}_{\mathrm{s}}, \mathrm{k}_{1}, \mathrm{k}_{2}$, and $\mathrm{K}_{\mathrm{s}}$. The $\mathrm{C}_{\mathrm{s}}$ was described by the Langmuir isotherm $\mathrm{k}_{1}$ and $\mathrm{k}_{2}$ were $0.26(\mathrm{ml} / \mathrm{g} / \mathrm{d})$ and $0.08(1 / \mathrm{d})$, which was obtained from laboratory measurements (Chen and Liao, 2004) and the $\mathrm{K}_{\mathrm{s}}$ was determined by Eq. (3)

$K_{S}=\frac{k_{2} C_{f}-k_{1} C_{W}}{C_{S}}$

The $\mathrm{K}_{\mathrm{s}}$ of fishponds \#1-\#4 were $7.2 \times 10^{-3}, 5.3 \times 10^{-3}, 2.6$ $\times 10^{-3}$, and $4.7 \times 10^{-4} \mathrm{~g} / \mathrm{g} / \mathrm{d}$, respectively, with a mean value of $\mathrm{K}_{\mathrm{s}}, 3.9 \times 10^{-3} \mathrm{~g} / \mathrm{g} / \mathrm{d}$. The aforementioned parameters and As concentrations of pond water (Table 2) were adopted to estimate the As concentration of tilapia in fishponds \#5-\#8 using Eqs (2) to estimate the steady-state As concentrations

Table 2 Measured total As concentrations in pond water and tilapia, and estimated equilibrium As concentrations of tilapia with and without considering the sediment phase of fishponds \#5-\#8

\begin{tabular}{lllll}
\hline Medium & Fishpond \# & & \\
\cline { 2 - 4 } & 5 & 6 & 7 & 8 \\
\hline Measured As in pond water $(\mu \mathrm{g} / \mathrm{L})$ & 11.7 & 10.4 & 15.9 & 6.7 \\
Measured As in tilapia $(\mu \mathrm{g} / \mathrm{kg})$ & 634.4 & 505.7 & 878.2 & 215.8 \\
Estimated As in tilapia including sediment phase $(\mu \mathrm{g} / \mathrm{kg})$ & $640.9(1.0)^{\mathrm{a}}$ & $572.9(13.3)$ & $863(-1.7)$ & $372.6(-72.7)$ \\
Estimated As in tilapia excluding sediment phase $(\mu \mathrm{g} / \mathrm{kg})$ & $38(-94.0)$ & $33.9(-93.3)$ & $51.6(-94.1)$ & $21.8(-89.9)$ \\
\hline
\end{tabular}

${ }^{a}$ relative error $(\%)=(($ estimated As in tilapia-measured As in tilapia $) /$ measured As in tilapia $) \times 100 \%$ 
in tilapia with the sediment phase $\left(\mathrm{K}_{\mathrm{s}}\right.$ set to $\left.3.9 \times 10^{-3} \mathrm{~g} / \mathrm{g} / \mathrm{d}\right)$ and without the sediment phase $\left(\mathrm{K}_{\mathrm{s}}\right.$ set to 0$)$. The estimated equilibrium As concentrations of tilapia in fishponds \#5-\#8 are shown in Table 2. The results of As concentrations in tilapia including the sediment phase were close to the field measurements $(p<0.05)$, whereas the simulated As concentrations in tilapia excluding the sediment phase accounted for only $11.8 \%-20.3 \%$ of the measured total As concentration in tilapia, leading to a significant error $(p<$ 0.05). To estimate the target cancer risk of As, the total As (Han et al., 1998) and inorganic As species (Liu et al., 2005) concentrations of tilapia, which were analyzed from field measurement, were adopted in the commonly used method of the US EPA Region 3 Risk-Based Concentration Table (US EPA 1996). The assessed risks, which are both higher than $10^{-6}$, indicate the existence of a potential health cancer risk. When the As concentrations of tilapia, which are obtained from the laboratory excluding the sediment phase were used, the assessed risks might be underestimated under the same level of As concentration in water. The lack of investigation into As concentration in the sediment phase in the aquacultural ecosystem may thus cause an inaccurate estimate of not only the As concentration in tilapia, but also the risk assessment.

Acknowledgments The authors would like to thank the National Science Council of the Republic of China for financially supporting this research under Contract No. NSC 91-2313-B-002-270.

\section{References}

Buschmann J, Kappeler A, Limdauer U, Kistler D, Berg M, Sigg L (2006) Arsenite and arsenate binding to dissolved humic acids: Influence of $\mathrm{pH}$, type of humic acid, and aluminum. Environ Sci Technol 40:6015-6020

Chen BC, Liao CM (2004) Farmed tilapia Oreochromis missambicus involved in transport and biouptake of arsenic in aquacultural ecosystems. Aquaculture 242:365-380
Donohue JM, Abernathy CO (1999) Exposure to inorganic arsenic from fish and shellfish. In: Chappell WR, Abernathy CO, Calderon RL (eds) Arsenic exposure and health effects. Elsevier Science Ltd, Oxford, UK, p 89-98

Donahue SJ, Heckendorn SE (1996) Laboratory procedures: Virginia Tech Soil Testing and Plant Analysis Laboratory. Virginia Cooperative Extension Bulletin 452-881

Han BC, Jeng WL, Chen RY, Fang GT, Hung TC, Tseng RJ (1998) Estimation of target hazard quotients and potential health risks for metals by consumption of seafood in Taiwan. Arch Environ Contam Toxicol 35:711-720

Huang YK, Lin KH, Chen HW, Chang CC, Liu CW, Yang MH, Hsueh YM (2003) As species contents at aquaculture farm and in farmed mouthbreeder (Oreochromis mossambicus) in BFD hyperendemic areas. Food and Chem Toxicol 41:1491-1500

Liao CM, Chen BC, Singh S, Lin MC, Liu CW, Han BC (2003) Acute toxicity and bioaccumulation of arsenic in tilapia (Oreochromis mossambicus) from a blackfoot disease area in Taiwan. Environ Toxicol 18:252-259

Lin MC, Lin HY, Cheng HH, Chen YC, Liao CM (2005) Risk Assessment of Arsenic Exposure from Consumption of Cultured Milkfish, Chanos chanos (Forsskål), from the Arsenic-Contaminated Area in Southwestern Taiwan. Bull Environ Contam Toxicol 75:637-644

Liu CW, Huang FM, Hsueh YM (2005) Revised cancer risk assessment of inorganic arsenic upon consumption of tilapia (Oreochromis mossambicus) from blackfoot disease hyperendemic areas. Bull Environ Contam Toxicol 74:1037-1044

Smedley PL, Kinniburgh DG (2002) A review of the source, behaviour and distribution of arsenic in natural waters. Appl Geochem 17:517-568

Suhendrayatna OA, Nakajima T, Maeda S (2002) Studies on the accumulation and transformation of arsenic in freshwater organisms II. Accumulation and transformation of arsenic compounds by Tilapia mossambica. Chemosphere 46:325331

Taiwan Environmental Protection Administration (2001) Survey and Examination of Aquacultural Water Quality in Taiwan Waters Taiwan Sugar Company (2004) Groundwater Quality of the Taiwan Groundwater Monitoring Network (1/2). Taiwan Water Resource Bureau

Tseng WP (1997) Effects and dose-response relationships of skin cancer and blackfoot disease with arsenic. Environ Health Perspect 19:109-119

US EPA (1996) Risk-Based Concentration Table, Region 3 U.S. Environmental Protection Agency, Philadelphia, PA 